\title{
Article
}

\section{The Influence of Interesterification on the Thermal and Technological Properties of Milkfat-Rapeseed Oil Mixture and Its Potential Use in Incorporation of Model Meat Batters}

\author{
Magdalena Wirkowska-Wojdyła ${ }^{1, *}$, Marta Chmiel ${ }^{2}$, Ewa Ostrowska-Ligęza ${ }^{1}$, Agata Górska ${ }^{1}$, Joanna Bryś ${ }^{1}$, \\ Mirosław Słowiński ${ }^{2}$ (1) and Agnieszka Czerniszewska ${ }^{1}$ \\ 1 Department of Chemistry, Institute of Food Sciences, Warsaw University of Life Sciences, 02-787 Warsaw, \\ Poland; ewa_ostrowska_ligeza@sggw.edu.pl (E.O.-L.); agata_gorska@sggw.edu.pl (A.G.); \\ joanna_brys@sggw.edu.pl (J.B.); agnieszka.czerniszewska@op.pl (A.C.) \\ 2 Department of Food Technology and Evaluation, Institute of Food Sciences, Warsaw University of Life \\ Sciences, 02-787 Warsaw, Poland; marta_chmiel@sggw.edu.pl (M.C.); miroslaw_slowinski@sggw.edu.pl (M.S.) \\ * Correspondence: magdalena_wirkowska@sggw.edu.pl; Tel.: +48-5937606
}

Citation: Wirkowska-Wojdyła, M.; Chmiel, M.; Ostrowska-Ligęza, E.; Górska, A.; Bryś, J.; Słowiński, M.; Czerniszewska, A. The Influence of Interesterification on the Thermal and Technological Properties of Milkfat-Rapeseed Oil Mixture and Its Potential Use in Incorporation of Model Meat Batters. Appl. Sci. 2021, 11,350. https://doi.org/ 10.3390/app11010350

Received: 23 November 2020 Accepted: 28 December 2020 Published: 31 December 2020

Publisher's Note: MDPI stays neutral with regard to jurisdictional clai$\mathrm{ms}$ in published maps and institutional affiliations.

Copyright: (C) 2020 by the authors. Licensee MDPI, Basel, Switzerland. This article is an open access article distributed under the terms and conditions of the Creative Commons Attribution (CC BY) license (https:// creativecommons.org/licenses/by/ $4.0 /)$.
Abstract: Enzymatic interesterification gives the possibility to obtain a wide range of lipids with a modified structure. In the present study, model meat batters were produced from chicken breast muscles and enzymatically interesterified fats: milkfat:rapeseed oil (3:2 w/w). Fatty acids composition and their positional distribution in triacylglycerol, melting profile and oxidative stability have been determined in fats used for interesterification, after interesterification and extracted from meat batters. In meat batters, the physiochemical parameters were determined. Interesterified fats were characterized by significantly lower induction times than noninteresterified fat $(85.29$ and $18.21 \mathrm{~min}$, respectively). Meat batters were also characterized by a lower oxidative stability of lipid fraction (24.90 and $13.67 \mathrm{~min}$ ) than lipids used to their production. A higher content of unsaturated fatty acids was found in meat batters with noninteresterified and interesterified fats $(69.40 \%$ and $70.03 \%$, respectively) than in the control meat batter with a pork jowl (58.63\%). In comparison to the control product, meat batter prepared with interesterified mixture was characterized by significantly lower apparent viscosity. In the analyzed meat batters, there were no differences in thermal drip and penetration force. The incorporation of interesterified milkfat with rapeseed oil in model meat batters can be a strategy to improve the nutritional quality without adversely affecting the quality characteristics.

Keywords: interesterification; fatty acids; meat batters; oxidation; DSC

\section{Introduction}

In the process of fat selection for the manufacture of products with a high content of the ingredient, special attention should be paid to its consistency and chemical composition. A high content of fat, especially rich in saturated fatty acids (SFA), is unacceptable to many consumers, who are looking for products with a reduced fat content or a more favorable share of unsaturated to saturated fatty acids. For the human body, saturated fatty acids are primarily a source of energy, but, unfortunately, they increase the level of cholesterol and triacylglycerols in the blood serum, which, consequently, can contribute to the development of coronary heart disease. A diet rich in saturated fatty acids is proven to be one of the reasons of cardiovascular diseases and susceptibility to the formation of blood clots by intensifying platelet aggregation and increasing the concentration of fibrinogen [1].

Fat is an inseparable component of all meat products, responsible for their tastiness and sensory acceptability. It provides the proper texture and juiciness to meat products, causes the desired gelling effect and influences the stability of meat emulsions, reducing the thermal cooking loss [2]. In addition, the reduction or absence of an oral "fat" sensation in meat products makes them unacceptable for a large group of consumers. 
Different nonanimal or modified fats have been utilized in order to change the fat composition in meat products [2-6]. The total content of unsaturated fatty acids in sausages can be increased by applying highly unsaturated vegetable oils in the production process [2]. It is worth mentioning that the partial or complete replacement of animal fat with vegetable oil can negatively affect the textural quality, appearance and oxidation stability of meat products [6,7]. Hyeon-Woong et al. [2] showed that the presence of unsaturated fatty acids in meat products might rapidly reduce the stability of the meat product. The liquid state of matter and high content of unsaturated fatty acids in vegetable oils are the most important reasons for these unfavorable effects [6,8]. One of the strategies to utilize plant oils in meat technology involves the use of interesterified vegetable oils [6].

Enzymatic interesterification gives the opportunity to obtain lipids with predetermined properties. During the reaction, the position of the acyl groups changes within and between the triacylglycerol molecules. This process does not alter the structure of fatty acids, and thus, the bioavailability of valuable unsaturated fatty acids remains unchanged $[9,10]$. Interesterification affects the melting and crystallization point of the oils, which gives the possibility to obtain a wide range of lipids with a modified structure and physicochemical properties [6]. The studies on obtaining interesterified lipids with the desired composition and distribution of fatty acids and altered melting profile can lead to designing new products with predetermined properties of high application potential in the food industry [10]. In previous studies, different interesterified plant oils (sunflower, soybean, palm, canola, cotton, cartamo, olive and maize oils) in different proportions were used to substitute pork backfat in sausages [3]. Kılıç and Özer [5,6] investigated the effect of replacing beef fat with interesterified palm kernel oil on the quality parameters of frankfurters and Turkish dry-fermented sausages. Cheong et al. [11] evaluated the physical and sensory characteristics of sausages produced from enzymatically interesterified blends of lard and rapeseed oil.

The objective of this study was to investigate the effect of replacing pork jowl with an interesterified mixture of milkfat with rapeseed oil on the physiochemical and technological parameters of model meat batters produced from chicken breast muscles. Rapeseed oil is currently considered the most valuable oil. It has an optimal fatty acid composition and the most favorable ratio of $n-6$ to $n-3$. Rapeseed oil is also the most popular oil used in Poland. The quality of the lipid mixtures used in the recipe of model meat batters and lipid fraction isolated from batters was also evaluated. The research presented in this publication is a continuation of the project carried out at the Department of Chemistry on the interesterification of, among others, milkfat with rapeseed oil.

\section{Materials and Methods}

\subsection{Preparation of Interesterified Mixture of Milkfat with Rapeseed Oil}

Enzymatic interesterification reaction of milkfat and rapeseed oil at weight ratio 3:2 was carried out using 1,3-specific lipase (Rhizomucor miehei) enzyme $8 \%$ at $70{ }^{\circ} \mathrm{C}$ for $4 \mathrm{~h}$. Purification of the interesterified fat was performed according to the procedure described by Jimenez et al. [12].

\subsection{Model Meat Batters Manufacturing}

Model meat batters were manufactured according to the method described by WirkowskaWojdyła et al. [13]. The recipes of meat batters are given in Table 1 . Three variants of meat batters were produced in three series: MB_C_-control meat batters with pork jowl, MB_MF:RSO_meat batters with noninteresterified mixture of milkfat with rapeseed oil and MB_iMF:RSO_meat batters with interesterified milkfat with rapeseed oil. The interesterified fat can be used in the production of homogenized or finely ground sausages for special nutritional purposes. In Poland, homogenized sausages (wiener-type sausages) contain $30 \%$ fat. Therefore, this amount of fat was also used in the production of meat batters, and this amount was replaced by esterified fats. 
Table 1. Composition of batters.

\begin{tabular}{cccc}
\hline Components & \multicolumn{3}{c}{ Share (\%) } \\
\cline { 2 - 4 } & MB_C & MB_MF:RSO & MB_iMF:RSO \\
\hline Chicken breast muscles & 70 & 70 & 70 \\
Milkfat & 0 & 18 & 0 \\
Rapeseed oil & 0 & 12 & 0 \\
Interesterified mixture of milkfat and rapeseed oil & 0 & 0 & 30 \\
Pork jowl & 30 & 0 & 0 \\
Water * & 20 & 20 & 2.1 \\
Curing salt * & 2.1 & 2.1 & 1.0 \\
Soy protein isolate * & 1.0 & 1.0 & 0.25 \\
Phosphate * & 0.25 & 0.25 & 0.05 \\
Sodium ascorbinate * & 0.05 & 0.05 & \\
\hline${ }^{*}$ In relation to the mass of meat and fat. MB_C-control meat batters with pork jowl, MB_MF:RSO-meat batters \\
produced with noninteresterified mixture of milkfat and rapeseed oil and MB_iMF:RSO—meat batters produced \\
with interesterified mixture of milkfat and rapeseed oil.
\end{tabular}

\subsection{Analysis of Physiochemical and Technological Parameters of Model Meat Batters}

Apparent viscosity; penetration force (texture) and $\mathrm{L}^{*}, \mathrm{a}^{*}$ and $\mathrm{b}^{*}$ color components were determined according to the procedure described by Wirkowska-Wojdyła et al. [13]. Thermal drip was determined according to the procedure described by Chmiel and Słowiński [14].

Apparent viscosity was determined in unheated meat batters. Thermal drip was evaluated after heat treatment. Color components and penetration force were measured under refrigerated temperature $\left(4-6^{\circ} \mathrm{C}\right)$ after $24 \mathrm{~h}$ of cooling of meat batters.

\subsection{Acid Value Analysis}

Acid values (AV) were determined according to the ISO method 660: 2009 [15] by titration of fat samples with 0.1-M ethanolic potassium hydroxide solution.

\subsection{Fatty Acids Composition/GC Analysis}

The fatty acids compositions of the initial fat, interesterified mixtures and fat extracted from samples were determined after converting the triacylglycerols into their methyl esters according to the ISO method [16]. The YL6100 (Young Lin Bldg., Anyang, Hogyedong, Korea) gas chromatograph equipped with a flame ionization detector and a BPX-70 capillary column (SGE Analytical Science, Milton Keynes, UK) were used. The procedure for analyzing fatty acid methyl esters has been described in previous studies [13].

The analysis of the percentage content of a fatty acid in the sn-2 position of triacylglycerols was based on the ability of selectively hydrolyzed ester bonds in the sn- 1,3 positions by the pancreatic lipase. The determination was done according to the procedure described by Bryś et al. [17].

\subsection{Oxidative Stability}

Pressure differential scanning calorimeter (DSC Q200 TA Instruments, Newcastle. WA, USA) was used to determine the oxidative stability of fats. The experiment was performed at $120^{\circ} \mathrm{C}$ under $1400 \mathrm{kPa}$ pressure of oxygen. The procedure was described in previous studies [18].

\subsection{Melting Profile}

Melting characteristics of noninteresterified and interesterified fats were analyzed according to the method described by Aguedo et al. [19] and Wirkowska-Wojdyła et al. [18]. Q200 DSC (TA Instruments, Newcastle, WA, USA) was used for measurements. 


\subsection{Statistical Analysis}

The results of each experiments were presented as mean with standard error values. The statistical analysis of the results was performed using the Statgraphics Plus, version 5.1 (Statistical Graphics Corporation, Warrenton, VA, USA) program. One-way analysis of variance (ANOVA) was used to analyze significant differences at a $p$-value of 0.05 , according to Tukey's multiple range test.

\subsection{The List of Abbreviations}

MF:RSO—noninteresterified mixture of milkfat and rapeseed oil, iMF:RSO—interesterified mixture of milkfat and rapeseed oil,

MB_C_-control meat batters with pork jowl,

MB_MF:RSO-meat batters produced with noninteresterified mixture of milkfat and rapeseed oil and

MB_iMF:RSO—meat batters produced with interesterified mixture of milkfat and rapeseed oil.

\section{Results and Discussion}

\subsection{Analysis of Interesterified and Noninteresterified Mixtures}

The fatty acid compositions in the initial (MF:RSO) and interesterified (iMF:RSO) mixtures are given in Table 2.

Table 2. Fatty acid compositions (\%) of fats used in the model meat batters and extracted from the model meat batters.

\begin{tabular}{|c|c|c|c|c|c|}
\hline Fatty Acid & MF:RSO & iMF:RSO & MB_C & MB_MF:RSO & MB_iMF:RSO \\
\hline C4:0 & $0.34 \pm 0.12^{\mathrm{a}}$ & $0.54 \pm 0.12^{a}$ & - & $0.36 \pm 0.04^{a}$ & $0.38 \pm 0.10^{\mathrm{a}}$ \\
\hline C6:0 & $0.34 \pm 0.11^{\mathrm{a}}$ & $0.55 \pm 0.10^{\mathrm{a}}$ & $0.15 \pm 0.06^{b}$ & $0.40 \pm 0.06^{\mathrm{a}}$ & $0.42 \pm 0.11^{\mathrm{a}}$ \\
\hline C8:0 & $0.30 \pm 0.10^{\mathrm{a}}$ & $0.43 \pm 0.10^{\mathrm{a}}$ & $0.08 \pm 0.02^{b}$ & $0.32 \pm 0.02^{\mathrm{a}}$ & $0.32 \pm 0.08^{a}$ \\
\hline C10:0 & $0.83 \pm 0.24^{\mathrm{a}}$ & $1.14 \pm 0.26^{\mathrm{a}}$ & $0.09 \pm 0.02^{b}$ & $0.81 \pm 0.08^{a}$ & $0.83 \pm 0.15^{\mathrm{a}}$ \\
\hline C12:0 & $1.16 \pm 0.38^{\mathrm{a}}$ & $1.44 \pm 0.32^{\mathrm{a}}$ & $0.22 \pm 0.05^{b}$ & $1.14 \pm 0.67^{\mathrm{a}}$ & $1.15 \pm 0.21^{\mathrm{a}}$ \\
\hline C14:0 & $4.50 \pm 0.95^{\mathrm{a}}$ & $4.82 \pm 0.58^{\mathrm{a}}$ & $1.61 \pm 0.51^{b}$ & $4.03 \pm 0.54^{\mathrm{a}}$ & $4.04 \pm 0.68^{a}$ \\
\hline C14:1 & $0.46 \pm 0.12^{\mathrm{a}}$ & $0.58 \pm 0.10^{a}$ & - & $0.47 \pm 0.09^{a}$ & $0.48 \pm 0.10^{a}$ \\
\hline C15:0 & $0.53 \pm 0.16^{\mathrm{a}}$ & $0.56 \pm 0.13^{a}$ & $0.08 \pm 0.02^{b}$ & $0.49 \pm 0.08^{a}$ & $0.48 \pm 0.121^{a}$ \\
\hline C15:1 & $0.11 \pm 0.05^{\mathrm{a}}$ & $0.11 \pm 0.05^{\mathrm{a}}$ & - & $0.10 \pm 0.05^{\mathrm{a}}$ & $0.10 \pm 0.05^{\mathrm{a}}$ \\
\hline C16:0 & $16.50 \pm 1.89^{a}$ & $15.39 \pm 1.26^{a}$ & $25.45 \pm 1.13^{b}$ & $15.37 \pm 1.12^{\mathrm{a}}$ & $15.15 \pm 1.29^{a}$ \\
\hline C16:1 & $0.68 \pm 0.16^{\mathrm{a}}$ & $0.82 \pm 0.21^{\mathrm{a}}$ & $3.03 \pm 0.54^{b}$ & $0.91 \pm 0.07^{\mathrm{a}}$ & $0.91 \pm 0.21^{\mathrm{a}}$ \\
\hline C17:0 & $0.32 \pm 0.11^{\mathrm{a}}$ & $0.29 \pm 0.06^{a}$ & $0.35 \pm 0.06^{\mathrm{a}}$ & $0.28 \pm 0.03^{a}$ & $0.27 \pm 0.05^{\mathrm{a}}$ \\
\hline C17:1 & $0.18 \pm 0.04^{\mathrm{a}}$ & $0.15 \pm 0.02^{\mathrm{a}}$ & $0.33 \pm 0.05^{b}$ & $0.14 \pm 0.01^{\mathrm{a}}$ & $0.14 \pm 0.03^{a}$ \\
\hline C18:0 & $6.32 \pm 0.99 \mathrm{a}$ & $5.40 \pm 0.61^{\mathrm{a}}$ & $12.42 \pm 1.05^{b}$ & $5.99 \pm 0.08^{a}$ & $5.66 \pm 0.32^{a}$ \\
\hline C18:1cis & $48.36 \pm 1.87^{\mathrm{a}}$ & $47.55 \pm 2.21^{a}$ & $44.27 \pm 2.26^{a}$ & $48.64 \pm 1.95^{\mathrm{a}}$ & $49.00 \pm 2.10^{a}$ \\
\hline C18:2trans & $0.14 \pm 0.05^{\mathrm{a}}$ & $0.13 \pm 0.05^{\mathrm{a}}$ & $0.14 \pm 0.06^{\mathrm{a}}$ & $0.12 \pm 0.04^{\mathrm{a}}$ & $0.11 \pm 0.03^{a}$ \\
\hline C18:2cis n-6 & $11.85 \pm 0.90^{\mathrm{a}}$ & $12.52 \pm 0.99^{a}$ & $9.58 \pm 0.94^{b}$ & $12.90 \pm 1.03^{a}$ & $13.12 \pm 1.34^{\mathrm{a}}$ \\
\hline C18:3cis n-6 & - & - & $0.10 \pm 0.03^{a}$ & $0.05 \pm 0.03^{\mathrm{a}}$ & $0.05 \pm 0.02^{\mathrm{a}}$ \\
\hline C18:3cis n-3 & $5.10 \pm 0.57^{\mathrm{a}}$ & $5.59 \pm 0.87^{a}$ & $0.58 \pm 0.06^{b}$ & $5.29 \pm 0.25^{\mathrm{a}}$ & $5.37 \pm 0.37^{a}$ \\
\hline C20:0 & $0.76 \pm 0.10^{\mathrm{a}}$ & - & $0.31 \pm 0.04^{b}$ & $0.81 \pm 0.07^{a}$ & $0.75 \pm 0.24^{\mathrm{a}}$ \\
\hline C20:1 & $0.85 \pm 0.11^{\mathrm{a}}$ & $0.88 \pm 0.11^{\mathrm{a}}$ & $0.74 \pm 0.04^{\mathrm{a}}$ & $0.90 \pm 0.08^{\mathrm{a}}$ & $0.86 \pm 0.10^{a}$ \\
\hline
\end{tabular}

Different letters ${ }^{\mathrm{a}, \mathrm{b}}$ indicate that the samples are considered significantly different at the $5 \%$ level $(p<0.05)$. MF:RSO—noninteresterified mixture of milkfat and rapeseed oil, iMF:RSO—interesterified mixture of milkfat and rapeseed oil, MB_C—control meat batters with pork jowl, MB_MF:RSO—meat batters produced with noninteresterified mixture of milkfat and rapeseed oil and MB_iMF:RSO-meat batters produced with interesterified mixture of milkfat and rapeseed oil.

Interesterification did not change the fatty acid compositions in the analyzed formulas. In the interesterified mixture, the share of individual fatty acids (FA) was found at a similar amount as in the initial fat mixture. Among the saturated fatty acids, palmitic acid was present in a dominant amount: $16.50 \%$ in MF:RSO and $15.39 \%$ in iMF:RSO. The major unsaturated fatty acids were oleic ( $48.36 \%$ in MF:RSO and $47.55 \%$ in iMF:RSO) and 
linoleic acid (11.85\% in MF:RSO and $12.52 \%$ in iMF:RSO). In both mixtures, $\alpha$-linolenic acid derived from rapeseed oil was also found. Its amount was at the level of $5.10 \%$ in the noninteresterified mixture and $5.59 \%$ in the interesterified fat. It is worth emphasizing that interesterification does not cause the isomerization of fatty acids and does not affect the degree of unsaturation [17,20-22]. Interesterification is a method of modifying the functionality of fats and oils [23]. The monitoring of the changes in interesterified fats is extremely useful and can be an indication about how the randomization process takes place [24]. In Figure 1, the analysis of fatty acids in the sn-2 position of the triacyglycerols is presented.

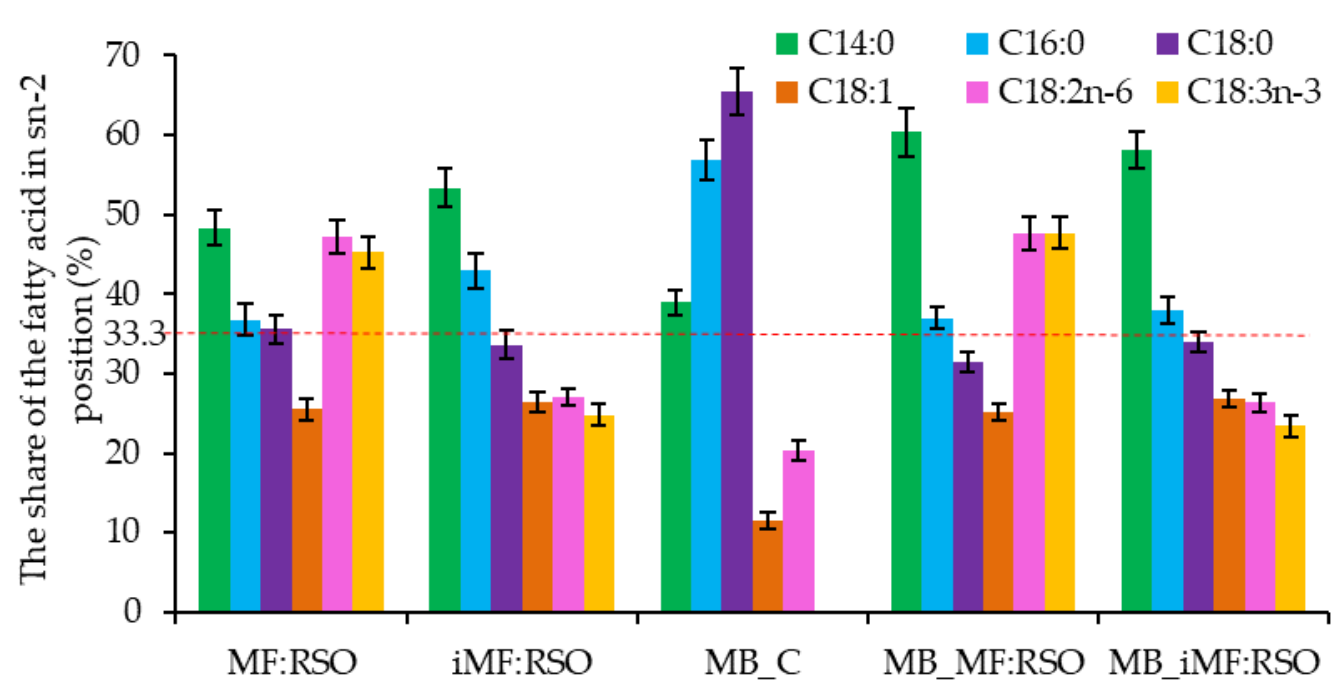

Figure 1. The percentage of fatty acids in the sn-2 position of the initial and interesterified fats and fats extracted from the model meat batters. MF:RSO—noninteresterified mixture of milkfat and rapeseed oil, iMF:RSO_interesterified mixture of milkfat and rapeseed oil, MB_C—control meat batters with pork jowl, MB_MF:RSO—meat batters produced with a noninteresterified mixture of milkfat and rapeseed oil and MB_iMF:RSO_meat batters produced with an interesterified mixture of milkfat and rapeseed oil.

The enzymatic preparation used in this experiment contains a regiospecific lipase. Thus, enzymatic interesterification should proceed only in the sn-1,3 position of triacylglycerols; the sn-2 position should remain unchanged $[25,26]$. In noninteresterified and interesterified fats, palmitic acid was mainly esterified in the sn-2 position $(36.81 \%$ and $42.91 \%$, respectively). The amount of unsaturated fatty acids in external positions (sn-1,3) in interesterified fats increased compared to the corresponding noninteresterified mixture. The percentage of unsaturated fatty acids in the internal position of TAG (triacylglycerol) in MF:RSO is $47.26 \%$ for linoleic acid and $45.29 \%$ for $\alpha$-linolenic acid, whereas, in iMF:RSO, reaches $27.02 \%$ and $24.81 \%$ for linoleic and $\alpha$-linolenic acid, respectively. The apparent lack of selectivity in the interesterification reaction catalyzed by the regiospecific lipase is due to the fact that the enzyme attacks mainly TAG at the sn-1,3 positions of the glycerol, yielding 1,2- and 2,3-diacylglycerols (DAGs), leaving the sn-2 position unchanged. The FA at the sn-2 position of the 1,2- and 2,3-DAG can spontaneously migrate, yielding the more stable 1,3-DAG [25]. It could result in reducing the amount of C18:2 and C18:3 acids in the sn-2 position of TAG in iMF:RSO. The rate and extent of fatty acid absorption depends on the stereochemistry of the modified lipids [27]. The pancreatic lipases release fatty acids from the sn- 1 and sn-3 positions of TAG, giving free fatty acids and a molecule of 2-monoacylglycerol, which are then absorbed. Studies of rats and human infants suggested that palmitic and stearic acids may be better absorbed when they are retained within 2-monoacylglycerol during digestion [23,28].

The melting profile determined the sensory characteristics of the final modified fat mixture. The melting curves of the blends before and after interesterification are presented 
in Figure 2. On the course of the curve of the initial blend, two distinct peaks can be observed: peak 1 corresponding with lower-melting TAGs from rapeseed oil and peak 2 corresponding with higher-melting TAGs from milkfat. This is in agreement with the fact that rapeseed oil is able to remain in liquid form at a wide range of temperatures due to the low content of saturated fatty acids [11]. The gradual decrease of peak 1 and appearance of a new peak 3 corresponding to a high-melting TAG was the main consequence of the interesterification. Peak 2 in the medium melting fraction became more pronounced. That can be attributed to the formation of new trisaturated and disaturated triacylglycerols after interesterification [24,29]. In the case of peak 3, the temperature associated with newly formed TAGs was very high, and a lot of energy was needed to melt the newly formed triacylglycerols, which also contributed to the increase of these blend melting points. Previous studies also indicated that the enzymatic interesterification process can cause changes in the melting profile $[13,18,24,29,30]$.

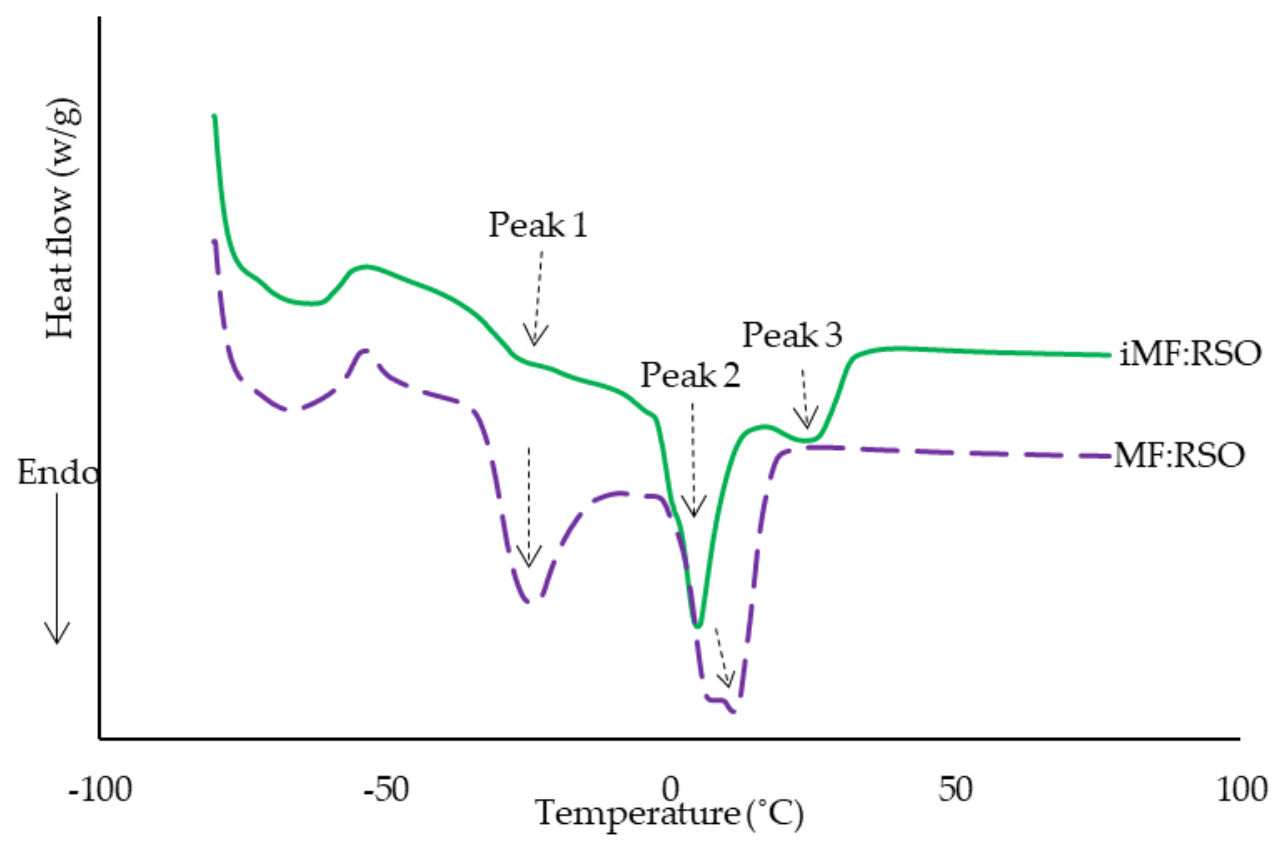

Figure 2. Melting curves of the initial and interesterified mixtures of milkfat with rapeseed oil. MF:RSO-noninteresterified mixture of milkfat and rapeseed oil and iMF:RSO_-interesterified mixture of milkfat and rapeseed oil.

The quality of the oils and fats used as raw materials in the interesterification is related to the free fatty acid (FFA) content, peroxide index, moisture and soaps content [24]. In the initial mixtures of milkfat with rapeseed oil, the acid value was at the level of $1.31-\mathrm{mg} \mathrm{KOH} / \mathrm{g}$ fat, and the oxidative stability expressed as the induction time reached $85.29 \mathrm{~min}$ (Figure 3).

The interesterified mixture was characterized by a significantly higher acid value ( $7.56 \mathrm{mg} \mathrm{KOH} / \mathrm{g}$ fat) than the initial mixture. Other research also reported that enzymatic interesterification caused an increase of the free fatty acids content $[10,17,31]$. It can be due to the fact that two opposite reactions occur in the process of enzymatic interesterification: partial hydrolysis and the resynthesis of esters, which means that, in the final product, some amount of free fatty acids are present [32]. Bryś et al. [31] state that the duration of the process significantly affects the FFA content.

Oliveira et al. [24] in research on the interesterification of palm stearin and patawa oil mixtures suggested that chemical interesterification, in turn, reduced the FFA content in fat blends, because during filtration, FFA could be removed with the catalyst. 


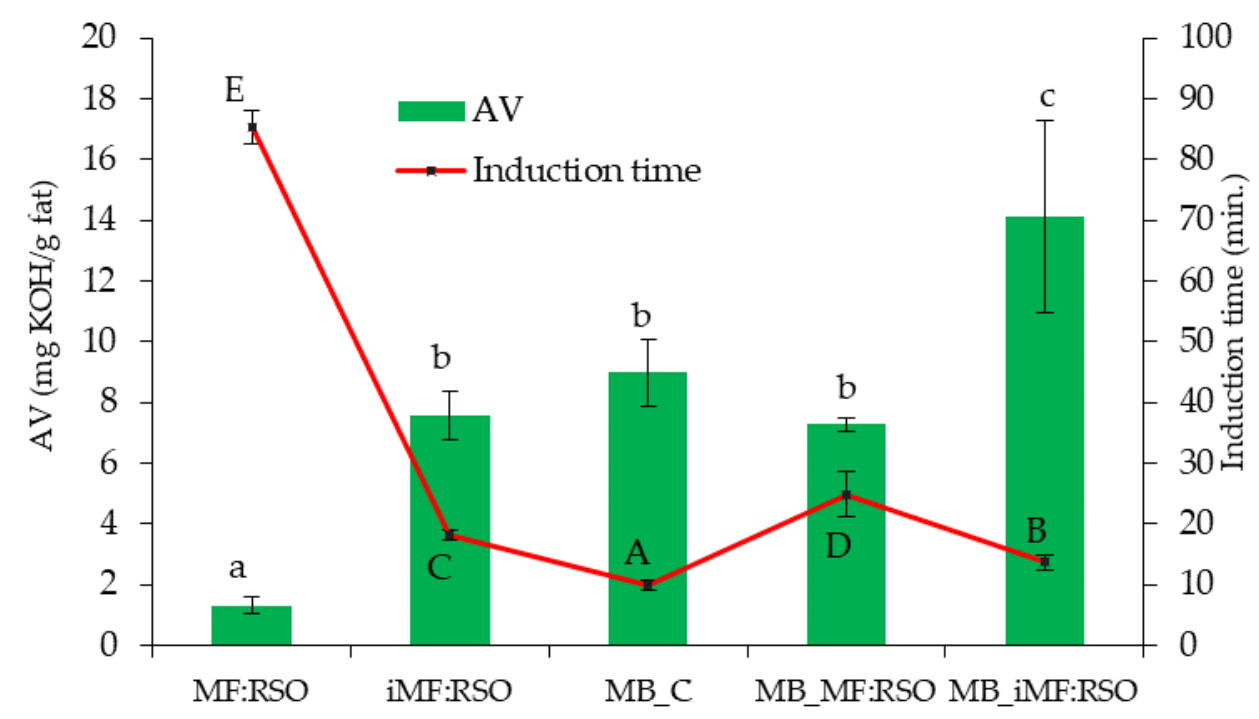

Figure 3. Acid value (AV) and induction time of fats used in model meat batters and extracted from model meat batters. Different letters indicate that the samples are considered significantly different at the $5 \%$ level $(p<0.05)$. MF:RSO—noninteresterified mixture of milkfat and rapeseed oil, iMF:RSO_interesterified mixture of milkfat and rapeseed oil, MB_C—control meat batters with pork jowl, MB_MF:RSO—meat batters produced with a noninteresterified mixture of milkfat and rapeseed oil and $M B \_i M F: R S O$ — meat batters produced with an interesterified mixture of milkfat and rapeseed oil.

The interesterified mixture was also characterized by a significantly lower induction time $(18.2 \mathrm{~min})$ than the noninteresterified blend (Figure 3). The main reason for the lower oxidative stability for structured lipids is the loss of the antioxidant during the interesterification reaction [33,34]. An important factor affecting the oxidative stability of interesterified fats is the distribution of fatty acids in triacylglycerol molecules. Most studies have shown that PUFA placed at the sn-2 location of TAG are more favorably oxidized than in the sn-1 and sn-3 locations [35,36]. Martin et al. [34] claimed that the effect of location of the fatty acids in the triacylglycerol position did not seem to be conclusive of the oxidative stability of the interesterified fats. Generally, most literature records a report that enzymatic interesterification caused a decrease in oxidative stability, regardless of the type of starting fats and reaction conditions $[13,17,18,31,34]$.

\subsection{Analysis of Lipid Fraction Extracted from Model Meat Batters}

The fatty acid compositions of the model meat batters is presented in Table 2. The incorporation of mixtures of MF:RSO and iMF:RSO in the recipe of model meat batters significantly changed the fatty acid composition compared with the control meat batters. It was found that meat batters MB_MF:RSO and MB_iMF:RSO were characterized by higher contents of polyunsaturated fatty acids (PUFA) and lower saturated fatty acids than the control meat batter (with pork jowl). In MB_MF:RSO and MB_iMF:RSO, the content of PUFA reached $18.24 \%$ and $18.54 \%$, respectively, while, in the MB_C, 10.26\%. The results revealed that the control meat batters were characterized by a higher amount of palmitic and stearic acids and lower amounts of linoleic and $\alpha$-linolenic acids than the meat batters with MF:RSO and iMF:RSO. The amount of oleic acid was at a similar level in all meat batters. In the case of the control meat batters, the lower values of the medium and short-chain fatty acids were determined. Medium-chain fatty acids are used in the body as a source of energy for the muscles, heart, liver, kidneys and platelets. They are also a source of fast energy, because they are easily absorbed in the small intestine and then transported through the portal vein to the liver, in which they are immediately metabolized [5]. Generally, the composition of fatty acids of model meat batters closely correlated with the types of fats used for their production. The amounts of individual fatty 
acids of the batters with the noninteresterified and interesterified mixtures were at similar level as in fats used for the production of batters. A previous study also reported that the replacement of animal fat with interesterified mixtures containing vegetable oil resulted in a more favorable from nutritional point of view ratio of unsaturated fatty acids to SFAs in the model meat batters [13], dry-fermented sausages [5], frankfurters [6] and sausages [11].

The distribution of fatty acids in the lipid fraction from the model meat batters reflects the distribution of these fatty acids in the appropriate fat mixtures used for the production of the mentioned products (Figure 1). The absorption of fatty acids in the intestinal lumen can be improved by achieving a specific distribution of fatty acids. If saturated fatty acids are esterified at the internal position of TAG, they are absorbed more efficiently compared to the saturated fatty esterified in the external positions of TAG [28]. Such modified lipids can be used in the production of special purpose foods. Studies on obtaining interesterified lipids with the desired compositions and distribution of fatty acids and, consequently, dealing with designing new products with predetermined properties seem to be particularly interesting $[5,6,23]$.

The content of free fatty acids was higher in fats isolated from the model meat batters than in fats used in the recipe of the meat batters (Figure 3). Fat from the meat batters was also characterized by lower oxidative stability than the corresponding fat mixtures. The reduction of oxidative stability may be caused by the hydrolysis of ester bonds in triacylglycerol molecules under the influence of water contained in the batters. The products of hydrolysis - mainly, free fatty acids — can induce an oxidation reaction. Despite the high content of unsaturated fatty acids in MB_MF:RSO and MB_iMF:RSO, the induction time values showed that the oxidative stability of the reformulated meat batters was higher than in the case of the control meat batter.

\subsection{Analysis of Physiochemical and Technological Parameters of Model Meat Batters}

Significant differences in the apparent viscosity of the obtained model meat batters were found (Table 3). The model meat batter prepared with an interesterified mixture of milkfat and rapeseed oil (MB_iMF:RSO) was characterized by a significantly $(p<0.05)$ lower apparent viscosity in comparison to the apparent viscosity of the control product (MB_C) and the meat batter with noninteresterified fat (MB_MF:RSO). Similar relationships were found by Wirkowska-Wojdyła et al. [13]. In these studies, lard, a mixture of lard and rapeseed oil and an interesterified mixture of lard and rapeseed oil were used for the production of chicken meat batters. It was found that modifications of the fats significantly affected the apparent viscosity of the produced meat batters. The significantly lowest viscosity was observed in the case of meat batter in which an interesterified mixture of lard and rapeseed oil was used. According to Lee et al. [33] and Choi et al. [37], there is a relationship between emulsion viscosity and its stability. Emulsions with low viscosity are easily broken. In turn, viscoelastic parameters of meat batters depend on the fat content and its structure. For example, the viscosity of the meat batters produced with higher and harder fat contents will be increased. However, this relationship is dependent on the temperature. Lower viscosity of the meat batters will result in a more efficient filling of the casings. Additionally, in the studies of Wirkowska-Wojdyła et al. [13], no significant differences in the thermal drip of produced chicken model meat batters with animal fat (lard), a mixture of lard and rapeseed oil or an interesterified mixture of lard and rapeseed oil were observed. However, the replacement of lard with a mixture of lard and rapeseed oil or interesterified mixture of lard and rapeseed oil significantly affected the texture of the meat batters. The meat batters produced with lard were characterized by significantly higher values of penetration force. 
Table 3. Technological parameters of the model meat batters.

\begin{tabular}{cccc}
\hline Parameters & MB_C & MB_MF:RSO & MB_iMF:RSO \\
\hline Apparent viscosity/10 ${ }^{-1}$ Pa s & $541.4 \pm 19.9^{\mathrm{a}}$ & $535.9 \pm 48.9^{\mathrm{a}}$ & $254.3 \pm 12.8^{\mathrm{b}}$ \\
Thermal drip/\% & $2.1 \pm 0.3^{\mathrm{a}}$ & $2.1 \pm 0.2^{\mathrm{a}}$ & $1.8 \pm 0,1^{\mathrm{a}}$ \\
Texture-penetration force N & $6.6 \pm 0.7^{\mathrm{a}}$ & $7.0 \pm 0.7^{\mathrm{a}}$ & $7.2 \pm 1.0^{\mathrm{a}}$ \\
Color components $\mathrm{L}^{*}$ & $77.8 \pm 1.8^{\mathrm{a}}$ & $83.2 \pm 0.8^{\mathrm{b}}$ & $84.0 \pm 0,6^{\mathrm{b}}$ \\
Color components $^{*}$ & $5.3 \pm 0.8^{\mathrm{a}}$ & $1.6 \pm 0.1^{\mathrm{b}}$ & $1.1 \pm 0.3^{\mathrm{b}}$ \\
Color components $^{*}$ & $7.7 \pm 0.2^{\mathrm{a}}$ & $11.3 \pm 0.4^{\mathrm{b}}$ & $10.8 \pm 0.3^{\mathrm{c}}$ \\
\hline
\end{tabular}

Different letters ${ }^{a, b, c}$ in a row indicate that the samples are considered significantly different at the $5 \%$ level $(p<0.05)$. MB_C — control meat batters with pork jowl, MB_MF:RSO—meat batters produced with a noninteresterified mixture of milkfat and rapeseed oil and MB_iMF:RSO-meat batters produced with an interesterified mixture of milkfat and rapeseed oil.

According to Decker and Park [38] and Cegiełka et al. [39], the replacement of the animal fatty raw material (e.g., pork jowl) with vegetable oil may have unfavorable effects on the technological quality of the meat product and, among others, can cause the increase of thermal loss. In our studies, there were no significant $(p>0.05)$ differences in the thermal drip and texture of the produced model meat batters (Table 3 ).

According to the literature [40,41], the substitution of animal fat with vegetable oil may change the color of meat products-for example, increased yellowness. Changes in meat batter colors were also observed in our studies (Table 3). Meat batters produced with noninteresterified or interesterified mixtures of milkfat and rapeseed oil (MB_MF:RSO and MB_iMF:RSO) were characterized by a significantly higher $(p<0.05)$ lightness ( $\mathrm{L}^{*}$ color component) and yellowness ( $\mathrm{b}^{*}$ color component) and significantly $(p<0.05)$ lower redness ( $\mathrm{a}^{*}$ color component).

\section{Conclusions}

The interesterification of milkfat with rapeseed oil caused the restructuring and formation of new triacylglycerols with varying degrees of saturation and a wide melting and plastic range. The use of such lipids did not adversely affect the technological properties of meat batters (texture and thermal drip). The incorporation of a milk fat and rapeseed oil interesterified mixture into meat batters resulted in a higher content of unsaturated fatty acids in the final products. Consequently, the content of $\alpha$-linolenic, beneficial from the nutritional point of view, was increased. The replacement of pork jowl with an interesterified mixture of milkfat with rapeseed oil improved the ratio between the n-3 and n- 6 fatty acids to more favorable level.

Author Contributions: Conceptualization, M.W.-W. and M.S.; methodology, M.W.-W., M.C. and E.O.-L.; formal analysis, A.C., E.O.-L. and J.B.; data curation, E.O.-L. and J.B.; writing-original draft preparation, M.W.-W. and writing - review and editing, A.G. and M.C. All authors have read and agreed to the published version of the manuscript.

Funding: This research received no external funding.

Institutional Review Board Statement: Not applicable.

Informed Consent Statement: Not applicable.

Data Availability Statement: Not applicable.

Conflicts of Interest: The authors declare no conflict of interest.

\section{References}

1. Vijayakumar, M.; Vasudevan, D.M.; Sundaram, K.R.; Krishnan, S.; Vaidyanathan, K.; Nandakumar, S.; Chandrasekhar, R.; Mathew, N. A randomized study of coconut oil versus sunflower oil on cardiovascular risk factors in patients with stable coronary heart disease. Indian Heart J. 2016, 68, 498-506. [CrossRef] [PubMed]

2. Hyeon-Woong, Y.; Jin-Kyu, S.; Jin-Yeon, J.; Gap-Don, K.M.; Shafiur, R.; Han-Sul, Y. The quality improvement of emulsion-type pork sausages formulated by substituting pork back fat with rice bran oil. Korean J. Food Sci. Anim. Resour. 2018, 38, 123-134. 
3. Ospina-E, J.C.; Cruz-S, A.; Pérez-Álvarez, J.A.; Fernández-López, J. Development of combinations of chemically modified vegetable oils as pork backfat substitutes in sausages formulation. Meat Sci. 2010, 84, 491-497. [CrossRef] [PubMed]

4. Alejandre, M.; Poyato, C.; Ansorena, D.; Astiasarán, I. Linseed oil gelled emulsion: A successful fat replacer in dry fermented sausages. Meat Sci. 2016, 121, 107-113. [CrossRef] [PubMed]

5. Kılıç, B.; Özer, C.O. Effects of replacement of beef fat with interesterified palm kernel oil on the quality characteristics of Turkish dry-fermented sausage. Meat Sci. 2017, 131, 18-24. [CrossRef] [PubMed]

6. K1lıç, B.; Özer, C.O. Potential use of interesterified palm kernel oil to replace animal fat in frankfurters. Meat Sci. 2019, 146, 206-212. [CrossRef]

7. Ospina-E, J.C.; Sierra-C, A.; Ochoa, O.; Perez-Alvarez, J.A.; Fernandez-Lopez, J. Substitution of saturated fat in processed meat products: A review. Crit. Rev. Food Sci. Nutr. 2012, 52, 113-122. [CrossRef]

8. Pappa, I.C.; Bloukas, J.G.; Arvanitoyannis, I.S. Optimization of salt, olive oil and pectin level for low-fat frankfurters produced by replacing pork backfat with olive oil. Meat Sci. 2000, 56, 81-88. [CrossRef]

9. Fauzi, S.H.M.; Rashid, N.A.; Omar, Z. Effects of chemical interesterification on the physicochemical, microstructural and thermal properties of palm stearin, palm kernel oil and soybean oil blends. Food Chem. 2013, 137, 8-17. [CrossRef]

10. Pacheco, C.; Palla, C.; Crapiste, G.H.; Carrin, M.E. Optimization of reaction conditions in the enzymatic interesterification of soybean oil and fully hydrogenated soybean oil to produce plastic fats. J. Am. Oil Chem. Soc. 2013, 90, 391-400. [CrossRef]

11. Cheong, L.-Z.; Zhang, H.; Nersting, L.; Jensen, K.; Haagensen, J.A.J.; Xu, X. Physical and sensory characteristic of pork sausages from enzymatically modified blends of lard and rapeseed oil during storage. Meat Sci. 2010, 85, 691-699. [CrossRef] [PubMed]

12. Jiménez, M.J.; Esteban, L.; Robles, A.; Hita, E.; González, P.A.; Muñío, M.M.; Molina, E. Production of triacylglycerols rich in palmitic acid at sn-2 position by lipase-catalyzed acidolysis. Biochem. Eng. J. 2010, 3, 95-198. [CrossRef]

13. Wirkowska-Wojdyła, M.; Bryś, J.; Ostrowska-Ligęza, E.; Górska, A.; Chmiel, M.; Słowiński, M.; Piekarska, J. Quality and oxidative stability of model meat batters as affected by interesterified fat. Int. J. Food Prop. 2019, 22, 607-617. [CrossRef]

14. Chmiel, M.; Słowiński, M. The use of computer vision system to detect pork defects. LWT Food Sci. Technol. 2016, 73, 473-480. [CrossRef]

15. ISO. Animal and Vegetable Fats and Oils—Determination of Acid Value and Acidity; International Organization for Standardization: Geneva, Switzerland, 2009; Volume 660.

16. ISO. Animal and Vegetable Fats and Oils_Preparation of Methyl esters of Fatty Acids; International Organization for Standardization: Geneva, Switzerland, 2001; Volume 5509.

17. Bryś, J.; Vaz Flores, I.F.; Wirkowska-Wojdyła, M.; Górska, A.; Ostrowska-Ligęza, E.; Bryś, A. Use of GC and PDSC methods to characterize human milk fat substitutes obtained from lard and milk thistle oil mixtures. J. Therm. Anal. Calorim. 2017, 130, 319-327. [CrossRef]

18. Wirkowska-Wojdyła, M.; Bryś, J.; Górska, A.; Ostrowska-Ligęza, E. Effect of enzymatic interesterification on physiochemical and thermal properties of fat used in cookies. LWT Food. Sci. Technol. 2016, 74, 99-105. [CrossRef]

19. Aguedo, M.; Giet, J.-M.; Hanon, E.; Logany, G.; Wathelet, B.; Destain, J.; Brasseur, R.; Vandenbol, M.; Danthine, S.; Blecker, C.; et al. Calorimetric study of milk fat/rapeseed oil blends and their interesterification products. Eur. J. Lipid Sci. Tech. 2009, 111, 376-385. [CrossRef]

20. Dogan, I.S.; Javidipour, I.; Akan, T. Effects of interesterified palm and cottonseed oil blends on cake quality. Int. J. Food Sci. Tech. 2007, 42, 157-164. [CrossRef]

21. Sharma, M.; Lokesh, B.R. Effect enzymatic trans- and interesterification on the thermal properties of groundnut and linseed oil and their blends. J. Am. Oil Chem. Soc. 2012, 89, 805-813. [CrossRef]

22. Dinç, S.; Javidipour, I.; Özbas, Ö.Ö.; Tekin, A. Utilization of zero-trans noninteresterified and interesterified shortenings in cookie production. J. Food Sci. Tech. 2014, 51, 365-370. [CrossRef]

23. Berry, S.E.; Bruce, J.H.; Steenson, S.; Stanner, S.; Buttriss, J.L.; Spiro, A.; Gibson, P.S.; Bowler, I.; Dionisi, F.; Farrell, L.; et al. Interesterified fats: What are they and why are they used? A briefin report from the Roundtable on Interesterified Fats in Foods. Nutr. Bull. 2019, 44, 363-380. [CrossRef]

24. Oliveira, P.D.; Rodrigues, A..; Bezerra, C.V.; Silva, L.H.M. Chemical interesterification of blends with palm stearin and patawa oil. Food Chem. 2017, 215, 369-376. [CrossRef] [PubMed]

25. Lopes, T.I.; Ribeiro, M.D.M.M.; Ming, C.C.; Grimaldi, R.; Gonçalves, L.A.G.; Marsaioli, A.J. Comparison of the regiospecific distribution from triacylglycerols after chemical and enzymatic interesterification of high oleic sunflower oil and fully hydrogenated high oleic sunflower oil blend by carbon-13 nuclear magnetic resonance. Food Chem. 2016, 212, 641-647. [CrossRef] [PubMed]

26. Pacheco, C.; Crapiste, G.H.; Carrín, M.E. Study of acyl migration during enzymatic interesterification of liquid and fully hydrogenated soybean oil. J. Mol. Catal. B Enzym. 2015, 122, 117-124. [CrossRef]

27. Farfán, M.; Villalón, M.J.; Ortíz, M.E.; Nieto, S.; Bouchon, P. The effects of interesterification on the bioavailability of fatty acids. Food Chem. 2013, 139, 571-577. [CrossRef]

28. Wang, T.; Wang, X.; Wang, X. Effects of lipid structure changed by interesterification on melting property and lipemia. Lipids 2016, 51, 1115-1126. [CrossRef]

29. Noor Lida, H.M.T.; Kalyana, S.; Nor Aini, I. DSC study on the melting properties of palm oil, sunflower oil, and palm kernel olein blends before and after chemical interesterification. J. Am. Oil Chem. Soc. 2006, 83, 739-745.

30. Jeyarani, T.; Yella Redy, S. Effect of enzymatic interesterification on physicochemical properties of mahua oil and kokum fat blend. Food Chem. 2010, 123, 249-253. [CrossRef] 
31. Bryś, J.; Vaz Flores, I.F.; Górska, A.; Ostrowska-Ligęza, E.; Bryś, A.; Niemiec, T.; Koczoń, P. The synthesis followed by spectral and calorimetric evaluation of stability of human milk fat substitutes obtained from thistle milk and lard. Int. J. Anal. Chem. 2019, 2019, 1-10. [CrossRef]

32. Xu, X. Production of specific-structured triacylglycerols bylipase-catalyzed reactions: A review. Eur. J. Lipid Sci. Tech. 2000, 102, 287-303. [CrossRef]

33. Lee, M.A.; Han, D.J.; Jeong, J.Y.; Choi, J.H.; Choi, Y.S.; Kim, H.Y.; Paik, H.D.; Kim, C.J. Effect of kimchi powder level and drying methods on quality characteristics of breakfast sausage. Meat Sci. 2008, 80, 708-714. [CrossRef] [PubMed]

34. Martin, D.; Reglero, G.; Senorans, F.J. Oxidative stability of structured lipids. Eur. Food Res. Technol. 2010, 231, 635-653. [CrossRef]

35. Endo, Y.; Hoshizaki, S.; Fujimoto, K. Autoxidation of synthetic isomers of triacylglycerol containing eicosapentaenoic acid. J. Am. Oil Chem. Soc. 1997, 74, 543-548. [CrossRef]

36. Endo, Y.; Hoshizaki, S.; Fujimoto, K. Oxidation of synthetic triacylglycerols containing eicosapentaenoic and docosahexaenoic acids: Effect of oxidation system and triacylglycerol structure. J. Am. Oil Chem. Soc. 1997, 74, 1041-1045. [CrossRef]

37. Choi, Y.S.; Choi, H.; Han, D.J.; Kim, H.Y.; Lee, M.A.; Kim, H.W.; Jeong, J.Y.; Kim, C.J. Characteristics of low-fat meat emulsion systems with pork fat replaced by vegetable oils and rice bran fiber. Meat Sci. 2009, 82, 266-271. [CrossRef]

38. Decker, E.A.; Park, Y. Healthier meat products as functional foods. Meat Sci. 2010, 86, 49-55. [CrossRef]

39. Cegiełka, A.; Chmiel, M.; Krajewska-Kamińska, E.; Hać-Szymańczuk, E. Quality characteristics of chicken burgers enriched with vegetable oils, inulin and wheat fiber. Ital. J. Food Sci. 2015, 3, 298-309.

40. Park, J.C.; Jeong, J.Y.; Lee, E.S.; Choi, J.H.; Choi, Y.S.; Yu, L.H.; Paik, H.D.; Cheon-Jei, K. Effects of replaced plant oils on the quality properties in low-fat hamburger patties. Korean J. Food Sci. Technol. 2005, 37, 412-417.

41. Yildız-Turp, G.; Serdaroğlu, M. Effect of replacing beef fat with hazelnut oil on quality characteristics of sucuk-A Turkish fermented sausage. Meat Sci. 2008, 78, 447-454. [CrossRef] 